\title{
Hypercalciuria is a common and important finding in postmenopausal women with osteoporosis
}

\author{
Sandro Giannini ${ }^{1,2}$, Martino Nobile ${ }^{1}$, Luca Dalle Carbonare ${ }^{1}$, Maria Giuseppina Lodetti ${ }^{1}$, Stefania Sella ${ }^{1}$, \\ Gabriele Vittadello ${ }^{1}$, Nadia Minicuci ${ }^{2}$ and Gaetano Crepaldi ${ }^{1,2}$ \\ ${ }^{1}$ Department of Medical and Surgical Sciences, Clinica Medica 1, University of Padua, Padua, Italy and ${ }^{2}$ National Research Council, \\ Institute of Neurosciences, Aging Unit of Padua, Padua, Italy
}

(Correspondence should be addressed to S Giannini, Department of Medical and Surgical Sciences, Clinica Medica I, University of Padua, Via Giustiniani, 2, 35128 Padua, Italy; Email: sandro.giannini@unipd.it)

\begin{abstract}
Objective and design: The prevalence and the effects of hypercalciuria on bone in patients with primary osteoporosis are poorly defined. We therefore retrospectively analyzed the data of 241 otherwise healthy women. They were 45-88 years of age and had been referred for their first visit to our Unit for Metabolic Bone Diseases over a 2-year period because of primary osteoporosis (bone density T-score $<-2.5$ ).

Methods: The main parameters of calcium and skeletal metabolism had been analyzed in all subjects. This population was then divided into two groups, according to the presence $(\mathrm{HC}+)$ or absence (HC-) of hypercalciuria.

Results: Elevated urinary calcium was present in $19 \%$ of the subjects. Due to the selection criteria, spinal and femoral bone loss was similar in the two groups. Urinary calcium, phosphate and fractional calcium excretion were higher in hypercalciuric patients. In a logistic regression model, the higher the Tm of phosphate, the lower the risk of hypercalciuria (odds ratio 0.33, confidence interval $0.18-0.62)$. On the contrary, hypercalciuria was the most important predictor of low bone mass in $\mathrm{HC}+$ (accounting for more than $50 \%$ of the variance in spinal bone density).

Conclusions: Hypercalciuria is a common feature in postmenopausal bone loss. Since increased urinary calcium excretion and low bone mass appear to be linked, hypercalciuria seems to be an important determinant of reduced bone density in this setting as well.
\end{abstract}

European Journal of Endocrinology 149 209-213

\section{Introduction}

Osteoporosis is a common disease which affects both women and men with a ratio of approximately 3:1 (1). It is characterized by low bone mass and microarchitectural deterioration of bone tissue that lead to an increase in bone fragility and consequent risk of fracture (2).

While in most patients with reduced bone mass there are no obvious factors that can be associated with the appearance of the disease, it is well known that many conditions can induce a secondary form of osteoporosis. These include a number of pharmacological treatments as well as some clinical disorders, such as hyperparathyroidism, hyperthyroidism, exogenous or endogenous hypercorticism, several intestinal disorders and many others (3).

The effect of idiopathic hypercalciuria on bone (defined as increased calcium excretion in the absence of secondary causes) has been widely evaluated in patients with calcium nephrolithiasis. Many authors have reported that the increase in urinary calcium excretion is associated with decreased bone mass and increased bone turnover in patients with kidney stones (4-6). Melton et al. (7) also reported an increased vertebral fracture risk in patients with urolithiasis.

It is generally agreed that hypercalciuria may be involved in the pathogenesis of low bone mass in patients referring for osteoporosis. However, the frequency and the pathogenetic relevance of this metabolic defect in osteoporotic patients have not been clearly described as yet. In a very recent paper focusing on the use of laboratory testing in revealing hidden alterations that can induce secondary osteoporosis, Tannenbaum and co-workers (8) found that hypercalciuria was the most common defect, being present in approximately $10 \%$ of their otherwise healthy 
osteoporotic women. However, in that study no attempt was made to correlate increased calcium excretion with low bone density.

The purposes of our study, therefore, were to evaluate the prevalence of hypercalciuria in a population of patients referring for the first time to our outpatient Unit for Metabolic Bone Diseases, and to assess the possible associations between hypercalciuria and bone density in this setting.

\section{Subjects and methods}

\section{Patients}

In a chart-review study we retrospectively examined the clinical records of 914 female outpatients consecutively referred to our Unit between 1 January 2000 and 31 December 2001 for a possible metabolic bone disease. Inclusion criteria were postmenopausal status and the presence of spinal or femoral osteoporosis (bone density T-score of $<-2.5$ standard deviations as compared with normal young adults). Pre- or perimenopausal women with spinal or femoral bone density higher than -2.5 standard deviations below the mean levels observed in normal young adults were excluded. Subjects with diseases (primary and secondary hyperparathyroidism, hyperthyroidism, renal tubular acidosis, medullary sponge kidney disease, multiple myeloma, sarcoidosis, hypercortisolism, liver or kidney failure, diabetes mellitus, severe gastrointestinal disorders, Paget's disease of bone) or taking drugs (corticosteroids, anti-convulsants, L-thyroxine, cyclosporin A, diuretics) known to influence bone and calcium metabolism were also excluded. From the remaining 302 postmenopausal women, aged 45-88 years (mean \pm s.D. age $64 \pm 7$ years, body mass index (BMI) $24 \pm 3 \mathrm{~kg} / \mathrm{m}^{2}$, daily calcium intake $685 \pm 202 \mathrm{mg}$ and time since menopause $15 \pm 8$ years), we further excluded 61 patients who were already taking medication for the treatment of bone loss (bisphosphonates, raloxifene, oestrogens, vitamin $\mathrm{D}$, fluoride and calcium supplements). The study was then carried out on a population of 241 postmenopausal women with osteoporosis, aged $45-88$ years.

\section{Assay methods}

All patients had undergone a clinical history and physical examination. Fasting blood and 24-h urine samples had been obtained in all subjects and analyzed for calcium, phosphate and creatinine (Automatic Analyzer; Technicon Instruments Corporation, Tarrytown, NY, USA). Serum bone alkaline phosphatase (b-ALP) isoenzyme in catalytic activity was determined by lectin from wheat germ precipitation (Iso-ALP; Boehringer Mannheim, Milan, Italy). After the total ALP activity had been determined (according to IFCC; Roche Diagnostics, Milan, Italy), b-ALP was precipitated using lectin from wheat germ as precipitant and the remaining ALP activity in the supernatant was measured (normal range: 5-56 U/l). This method has intra- and interassay coefficients of variation $<4$ and $<10 \%$ respectively, and it has a good correlation with an immunoradiometric assay measuring bone ALP mass concentration (9). Intact parathyroid hormone (PTH) was evaluated by a commercial immunoradiometric assay (Biorad Laboratories, Milan, Italy; normal range $10-60 \mathrm{pg} / \mathrm{ml})$, with intra- and interassay coefficients of variation of 6 and $8 \%$ respectively.

Daily dietary calcium intake was assessed by a validated questionnaire (10). The presence of hypercalciuria was first defined as urinary calcium excretion higher than $250 \mathrm{mg} /$ day or $4 \mathrm{mg} / \mathrm{kg}$ body weight per day on a free diet. (4). In order to exclude dietetic sources of increased urinary calcium excretion, hypercalciuric patients underwent a further 24-h urine collection after a 10-day normocaloric diet containing $1000 \mathrm{mg}$ calcium, $100 \mathrm{mmol}$ sodium, $60 \mathrm{mmol}$ potassium and $1 \mathrm{~g}$ protein $/ \mathrm{kg}$ body weight.

Fractional calcium excretion and the Tm values of phosphate were calculated according to standard formulas.

\section{Bone densitometry}

Dual X-ray absorptiometry (DXA) evaluation of the lumbar spine $\left(\mathrm{L}_{2}-\mathrm{L}_{4}\right)$ was performed by Hologic QDR 4500 (Hologic Corporation, Waltham, MA, USA) in all patients. DXA scans of the proximal femur were also obtained. The results are expressed as bone mineral density (BMD; $\mathrm{g} / \mathrm{cm}^{2}$ ) T- and Z-score (number of standard deviations of difference between the patient's BMD value and the BMD level of normal young adults or sex- and age-matched normal controls respectively). The T- and Z-scores were calculated using the manufacturer's normal values. The in vivo coefficient of variation, calculated as described in detail elsewhere (11), was $1.06 \%$ for the spine, $1.16 \%$ for the total femur and $1.63 \%$ for the femoral neck.

\section{Statistical analysis}

The results are expressed as means \pm S.D. Two-sample Student's $t$-test was performed to determine statistical differences between means. Logistic regression and stepwise multiple regression analyses were used to evaluate the relationships between the variables. $P$ values less than 0.05 were considered to be statistically significant. An SPSS package 10.1 version was used.

\section{Results}

The main clinical and metabolic parameters of the 241 patients enrolled are summarized in Table 1 . The T-scores of the lumbar spine, total hip and femoral 
Table 1 Clinical and biochemical parameters in the whole patient population $(n=241)$.

\begin{tabular}{lcc}
\hline & Patients & Normal values \\
\hline Age (years) & $64 \pm 7$ & \\
Years since menopause & $15 \pm 8$ & \\
BMl $\left(\mathrm{kg} / \mathrm{m}^{2}\right)$ & $24 \pm 3$ & \\
Dietary Ca intake $(\mathrm{mg} / \mathrm{day})$ & $685 \pm 202$ & \\
Serum creatinine $(\mathrm{mg} / \mathrm{dl})$ & $0.84 \pm 0.15$ & $0.7-1.2$ \\
Serum calcium $(\mathrm{mg} / \mathrm{dl})$ & $9.4 \pm 0.5$ & $8.6-10.5$ \\
Serum phosphate $(\mathrm{mg} / \mathrm{dl})$ & $3.5 \pm 0.5$ & $2.5-4.2$ \\
PTH $(\mathrm{pg} / \mathrm{ml})$ & $47 \pm 22$ & $10-55$ \\
b-ALP $(\mathrm{U} / \mathrm{l})$ & $34 \pm 19$ & $5-50$ \\
Urinary calcium (mg/day) & $174 \pm 91$ & $60-250$ \\
Urinary phosphate (mg/day) & $703 \pm 273$ & $400-1250$ \\
\hline
\end{tabular}

neck were $-3.3 \pm 0.7,-2.2 \pm 0.7$ and $-2.4 \pm 0.6$ respectively.

According to the 24-h urinary calcium excretion, this population was then divided into two groups: 46 patients $(19.1 \%)$ with a hypercalciuria of undetermined origin $(\mathrm{HC}+)$ and 195 without $(\mathrm{HC}-)$. The main clinical and metabolic parameters of the two groups are summarized in Table 2. The groups did not differ as to the main serum variables, apart from 24-h urinary calcium which, by definition, was higher in $\mathrm{HC}+$ $(312 \pm 51 \mathrm{mg})$ as compared with $\mathrm{HC}-$ patients (136 $\pm 56 \mathrm{mg}$ ), and 24-h urinary phosphate, Tm phosphate and fractional calcium excretion, which were higher in patients classified as hypercalciuric (Table 2).

Bone density T-scores of the spine and femur did not differ between the two groups (Table 3). When the small difference in age was taken into account (Z-scores), bone density was still similar between patients with or without hypercalciuria.

To adjust correlation analysis for possible confounders, two different regression analysis models were devised. The first one was a logistic regression, using urinary calcium excretion (as a dummy for the absence or presence of hypercalciuria, $\mathrm{HC}-=0$ and $\mathrm{HC}+=1$ )

Table 2 Clinical and biochemical parameters in patients with $(\mathrm{HC}+)$ or without $(\mathrm{HC}-)$ hypercalciuria.

\begin{tabular}{lccc}
\hline & $\begin{array}{c}\text { HC- } \\
(\boldsymbol{n}=\mathbf{1 9 5})\end{array}$ & $\begin{array}{c}\text { HC+ } \\
(\boldsymbol{n}=\mathbf{4 6})\end{array}$ & $\boldsymbol{P}$ \\
\hline Age (years) & $64 \pm 7$ & $63 \pm 7$ & $\mathrm{~ns}$ \\
Years since menopause & $16 \pm 8$ & $14 \pm 9$ & $\mathrm{~ns}$ \\
BMl (kg/m $\left.{ }^{2}\right)$ & $24 \pm 3$ & $24 \pm 3$ & $\mathrm{~ns}$ \\
Dietary Ca intake (mg/day) & $678 \pm 195$ & $709 \pm 227$ & $\mathrm{~ns}$ \\
Serum creatinine (mg/dl) & $0.85 \pm 0.15$ & $0.82 \pm 0.14$ & $\mathrm{~ns}$ \\
Serum calcium (mg/dl) & $9.4 \pm 0.5$ & $9.3 \pm 0.5$ & $\mathrm{~ns}$ \\
Serum phosphate (mg/dl) & $3.5 \pm 0.5$ & $3.5 \pm 0.6$ & $\mathrm{~ns}$ \\
PTH (pg/ml) & $47 \pm 22$ & $45 \pm 24$ & $\mathrm{~ns}$ \\
b-ALP (U/l) & $35 \pm 18$ & $34 \pm 23$ & $\mathrm{~ns}$ \\
Urinary phosphate (mg/day) & $632 \pm 217$ & $964 \pm 301$ & $<0.001$ \\
FECa & $1.5 \pm 1.7$ & $3.5 \pm 2.9$ & $<0.0001$ \\
Tm Pi (mg/dl) & $2.8 \pm 0.6$ & $2.3 \pm 0.8$ & $<0.0001$ \\
& & & \\
\hline
\end{tabular}

ns, not significant. FECa, fractional excretion of calcium.
Table 3 Bone densitometry data in patients with $(\mathrm{HC}+)$ or without $(\mathrm{HC}-)$ hypercalciuria.

\begin{tabular}{lccc}
\hline & HC $-(\boldsymbol{n}=\mathbf{1 9 5})$ & $\mathbf{H C}+(\boldsymbol{n}=\mathbf{4 6})$ & $\boldsymbol{P}$ \\
\hline T-score & & & \\
$\quad$ Lumbar spine & $-3.2 \pm 0.7$ & $-3.1 \pm 0.6$ & $\mathrm{~ns}$ \\
$\quad$ Total hip & $-2.2 \pm 0.7$ & $-2.0 \pm 0.6$ & $\mathrm{~ns}$ \\
$\quad$ Femoral neck & $-2.4 \pm 0.6$ & $-2.3 \pm 0.8$ & $\mathrm{~ns}$ \\
Z-score & & & \\
$\quad$ Lumbar spine & $-1.7 \pm 0.8$ & $-1.7 \pm 0.7$ & $\mathrm{~ns}$ \\
$\quad$ Total hip & $-1.0 \pm 0.7$ & $-0.9 \pm 0.8$ & $\mathrm{~ns}$ \\
Femoral neck & $-1.0 \pm 0.6$ & $-0.8 \pm 0.6$ & $\mathrm{~ns}$ \\
\hline
\end{tabular}

ns, not significant.

as a dependent variable, and age, BMI, Tm phosphate, dietary calcium intake, PTH and b-ALP as the predictive values. Only Tm phosphate was maintained by the model as a significant predictor (odds ratio (OR) 0.33, 95\% confidence interval (C.I.) 0.18-0.62).

The second multiple regression analysis model included the spinal T-score as a dependent variable, and age, BMI, time since menopause, dietary calcium intake, b-ALP, PTH, urinary calcium and phosphate excretions, and a dummy coded 0 for the absence $(\mathrm{HC}-)$ and 1 for the presence $(\mathrm{HC}+)$ of hypercalciuria, as the predictive values. When this model was applied to the whole population only BMI, years since menopause and urinary calcium excretion were left significantly associated with the outcome (Table 4). Because of the different and specific meaning of urinary calcium in hypercalciuric patients, we also wanted to evaluate the predictive value of the same variables (with the exclusion of the dummy) on bone density in this specific population (Table 5). In this model, only age and urinary calcium remained as significant predictors, with hypercalciuria explaining, by itself, more than $50 \%$ of spinal bone mass.

When patients with a more severe degree of spinal osteoporosis were considered (T-score $\leq-3.0$ ), only urinary calcium and time since menopause entered in the model as predictive variables in $\mathrm{HC}+$ patients $\left(\mathrm{R}^{2}=0.61, \quad \mathrm{P}=0.015\right)$, with calciuria explaining $38 \%$ of the variance in spinal bone density.

When hypercalciuric patients were divided according to total hip T-score $(<-3.0$ vs $\geq-3.0)$, urinary calcium excretion was significantly higher in patients with

Table 4 Multiple regression analysis in the whole population of patients, with spinal T-score as a dependent variable $\left(R^{2}=13 \%\right)$.

\begin{tabular}{lcc}
\hline & $\boldsymbol{\beta}$ & $\boldsymbol{P}$ \\
\hline $\mathrm{BMI}$ & 0.19 & 0.005 \\
Years since menopause & -0.28 & $<0.0001$ \\
Urinary Ca & -0.38 & 0.008 \\
$\mathrm{HC}-/ \mathrm{HC}+{ }^{a}$ & 0.21 & 0.06 \\
\hline
\end{tabular}

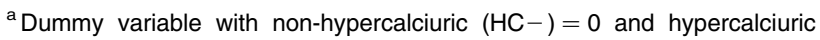
patients $(\mathrm{HC}+)=1$. 
Table 5 Multiple regression analysis in patients with hypercalciuria $(\mathrm{HC}+)$, with spinal $\mathrm{T}$-score as a dependent variable $\left(R^{2}=61 \%\right)$.

\begin{tabular}{lcc}
\hline & $\boldsymbol{\beta}$ & $\boldsymbol{P}$ \\
\hline Age & -0.35 & 0.03 \\
Urinary Ca & -0.72 & $<0.0001$ \\
\hline
\end{tabular}

the worst degree of osteoporosis $(359 \pm 44$ vs $308 \pm 50$, $P<0.05)$.

\section{Discussion}

No clear-cut indications for the inclusion or exclusion of urinary calcium excretion measurement as a firstline diagnostic tool in patients with osteoporosis are currently available. This probably occurs because there are no comprehensive data on the prevalence and the role of this defect in postmenopausal women with low bone density.

Our study demonstrates that an apparently primary form of hypercalciuria is present in up to $19 \%$ of postmenopausal women with osteoporosis. The only data concerning this issue have been recently published by Tannenbaum and co-workers (8), who conducted a chart-review study on otherwise healthy women with osteoporosis. By means of laboratory testing, they observed that a cumulative proportion of $32 \%$ of their patients had a secondary form (unexpected on a clinical basis) of decreased bone mass, with $10 \%$ of these subjects showing hypercalciuria. This alteration was by far the most frequent that they found in these patients. In our study, the prevalence of hypercalciuria was much higher than that in the paper by Tannenbaum et al. (8). However, while we used a classical definition of hypercalciuria (4), they referred to a different (and higher) normal range for urinary calcium (12), having enrolled oestrogen-deprived or -replete patients and on very different dietary calcium intakes. Even taking into account these differences, the two studies share the finding that hypercalciuria is surprisingly common in patients with a 'primary' form of osteoporosis.

Even fewer data exist on the meaning of hypercalciuria in postmenopausal osteoporosis. The relationships between bone metabolism and idiopathic hypercalciuria have been extensively studied in patients with calcium nephrolithiasis. In these subjects, the presence of reduced bone density has been clearly found to be related to the increased urinary calcium excretion (13). Our study may only partially help in addressing the issue of a possible cause-effect relationship between hypercalciuria and osteoporosis in those women carrying this defect. However, our data show that spinal bone mass is largely influenced by the increased calcium excretion in hypercalciuric patients. Accordingly, urinary calcium excretion was higher in hypercalciuric patients with the worst degree of femoral osteoporosis. These observations suggest that hypercalciuria is a specific and important landmark of this form of osteoporosis. The absence of differences in bone density between patients with and without hypercalciuria does not argue against this hypothesis. Indeed, because of the selection criteria, only patients with osteoporosis have been recruited and this has made differentiation of patients in terms of severity of bone loss rather unlikely.

Several considerations may strengthen the importance and the specificity of the relationship between osteoporosis and hypercalciuria. An increased risk of fractures has been reported in patients with urolithiasis (7). Although the reason for this remains unclear, hypercalciuria, which is present in up to $60-70 \%$ of these patients (14), may be one of the factors involved. Accordingly, low bone density has been reported by most authors in nephrolithiasic patients with hypercalciuria, but not in those without $(6,15-17)$. Furthermore, several retrospective and prospective studies have shown that thiazide use is associated with a reduction in fracture incidence (18-22) and an increase in bone density (23-25). In addition, although thiazides may act directly on bone resorption $(24,25)$, the reduction of renal calcium excretion remains the most important contributing factor to the improvement in bone density detected in thiazide-treated subjects (23-25).

This study has some limitations. Its design was retrospective and thus it was impossible to define the pathogenesis and type of hypercalciuria (diet dependent or independent). For the same reason, intestinal calcium absorption and dietary protein intake were not measured in these patients. However, subjects with secondary causes of hypercalciuria were not included. In addition, it seems rather unlikely that a diet-dependent form of hypercalciuria may have predominantly occurred in our patients, because dietary calcium intake was generally low. This also suggests that the majority of our patients might suffer from a diet-independent form of hypercalciuria, similar to that seen in patients with kidney stones and low bone density $(6,16,17,26)$. In addition, hypercalciuric patients showed increased fractional calcium excretion, which seems to indicate that at least part of the increase in urinary calcium may not depend upon intestinal calcium absorption. The reduced Tm phosphate values in these patients further strengthen this hypothesis. Finally, elevated urinary calcium excretion was confirmed after a diet with a normal amount of dietary proteins, and an excessive protein intake seems rather unlikely to be common in patients at this age.

In conclusion, hypercalciuria is a very frequent feature in women with reduced bone density. Increased urinary calcium excretion and bone loss appear to be linked, and these subjects seem to suffer from a peculiar form of osteoporosis. Consequently, urinary calcium excretion should be measured in osteoporotic patients in order to identify those patients reporting this specific alteration. 


\section{References}

1 Cooper C \& Melton LJ III. Epidemiology of osteoporosis. Trends in Endocrinoogy and Metabolism 1992314 224-229.

2 Consensus Development Conference. Prophylaxis and treatment of osteoporosis. American Journal of Medicine 199190 107-110.

3 Meunier PJ. Glucocorticoid-induced osteoporosis and other forms of secondary osteoporosis. In Osteoporosis: Diagnosis and Management, pp 233-250. Ed PJ Meunier. London: Martin Dunitz Ltd, 1998.

4 Bataille P, Achard JM, Fournier A, Boudailliets B, Westeel PF, el Esper $\mathrm{N}$ et al. Diet, vitamin D and vertebral mineral density in hypercalciuric calcium stone formers. Kidney International $1991391193-1205$.

5 Borghi L, Meschi T, Guerra A, Maninetti L, Pedrazzoni M, Marcato A et al. Vertebral mineral content in diet-dependent and diet-independent hypercalciuria. Journal of Urology 1991 146 1334-1338.

6 Giannini S, Nobile M, Sartori L, Calò L, Tasca A. Dalle Carbonare L et al. Bone density and skeletal metabolism are altered in idiopathic hypercalciuria. Clinical Nephrology 199850 94-100.

7 Melton LJ III, Crowson CS, Khosla S, Wilson DM \& O'Fallon WM. Fracture risk among patients with urolithiasis: a populationbased cohort study. Kidney International 199853 459-464.

8 Tannenbaum C, Clark J, Schwartzman K, Wallenstein S, Lapinski R, Meier D et al. Yield of laboratory testing to identify secondary contributors to osteoporosis in otherwise healthy women. Journal of Clinical Endocrinology and Metabolism 2002 $874431-4437$.

9 Zaninotto M. Bernardi D, Ujka F, Sciacovelli L, De Paoli M \& Plebani M. Clinical usefulness of bone ALP activity and mass concentration in bone disease. Clinical Chemistry Enzyme Communications 19988 83-89.

10 Angbrat M \& Möller M. Questionnaire about calcium intake: can we trust the answers? Osteoporosis International $1999 \mathbf{9}$ $220-225$.

11 Giannini S, D’Angelo A, Sartori L, Passeri G, Dalle Carbonare L \& Crepaldi G. Continuous and cyclical clodronate therapies and bone density in postmenopausal bone loss. Obstetrics and Gynecology $1996 \mathbf{8 8} 431-436$.

12 Heaney RP, Recker RR \& Ryan RA. Urinary calcium in perimenopausal women: normative values. Osteoporosis International 1999 9 13-18.

13 Weisinger JR. Bone loss in hypercalciuria: cause or consequence? American Journal of Kidney Diseases 199933 xlvi--xlviii.

14 Vosburgh E \& Peters TJ. Pathogenesis of idiopathic hypercalciuria: a review. Journal of Royal Society of Medicine 198780 34-37.
15 Barkin J, Wilson DR, Manuel MA, Bayley A, Murray T \& Harrison J. Bone mineral content in idiopathic calcium nephrolithiasis. Mineral and Electrolyte Metabolism 198511 19-24.

16 Pacifici R, Rothstein M, Rifas L, Lau KH, Baylink DJ, Avioli LV et al. Increased monocyte interleukin-1 activity and decreased vertebral bone density in patients with fasting idiopathic hypercalciuria. Journal of Clinical Endocrinology and Metabolism 1990 71 138-145.

17 Pietschmann F, Breslau NA \& Pak CYC. Reduced vertebral bone density in hypercalciuric nephrolithiasis. Journal of Bone and Mineral Research 199212 1383-1388.

18 Feskanich D, Willett WC, Stampfer MJ \& Colditz JA. A prospective study of thiazide use and fractures in women. Osteoporosis International 19977 79-84.

19 LaCroix AZ, Wienpahl J, White LR, Wallace RB, Scherr PA, George LK et al. Thiazide diuretic agents and the incidence of hip fracture. New England Journal of Medicine $1990 \mathbf{3 2 2}$ 286-290.

20 Nguyen TV, Eisman JA, Kelly PJ \& Sambrook PN. Risk factors for osteoporotic fractures in elderly men. American Journal of Epidemiology $1996 \mathbf{1 4 4} 255-263$.

21 Cauley JA. Cummings SR, Seeley DJ, Black D, Browner W, Kuller LH et al. Effects of thiazide diuretic therapy on bone mass, fractures and falls. The Study of Osteoporotic Fractures Research Group. Annals of Internal Medicine 1993118 666-673.

22 Felson DT, Sloutskis D, Anderson JJ, Anthony JM \& Kiel DP. Thiazide diuretics and the risk of hip fracture. Results from the Framingham Study. Journal of the American Medical Association $1991265370-373$.

23 Adams IS, Cindy F, Song BS \& Kantorovich V. Rapid recovery of bone mass in hypercalciuric, osteoporotic man treated with hydrochlorothiazide. Annals of Internal Medicine $1999 \mathbf{1 3 0}$ 658-660.

24 Reid IR, Ames RW, Orr-Walker BJ, Clearwater JM, Horne AM, Evans MC et al. Hydrochlorothiazide reduces loss of cortical bone in normal postmenopausal women: a randomized controlled trial. American Journal of Medicine 2000109 362-370.

25 LaCroix AZ, Ott SM, Ichikawa MS, Scholes D \& Barlow WE. Lowdose hydrochlorothiazide and preservation of bone mineral density in older adults. Annals of Internal Medicine $2000 \mathbf{1 3 3}$ $516-526$.

26 Tasca A, Cacciola A, Ferrarese P, Ioverno E, Visonà E, Bernardi C et al. Bone alterations in patients with idiopathic hypercalciuria and calcium nephrolithiasis. Urology 200259 865-869.

Received 31 January 2003

Accepted 5 June 2003 